\title{
Gainazal-topografiak naturan duen eragina
}

\section{Effect of surface topography on nature}

\author{
Nagore Barroso, Maria Isabel Moreno, Leyre Perez* \\ Kimika Makromolekularreko Laborategia, \\ Zientzia eta Teknologia Fakultatea (ZTF/FCT), \\ Euskal Herriko Unibertsitatea (UPV/EHU)
}

LABURPENA: Naturan auto-garbiketa edo bakterioen aurkako propietate bitxiak aurkezten duten izaki bizidun ugari daude. Lan honetan, ñame edo loto lorea bezalako landareak eta zenbait animaliak aurkezten dituzten propietateak, auto-garbitzeko gaitasuna edo bakterioen aurkako propietateak azalduko dira, esate baterako, hauen gainazaleko topografiaren eta bustitze-ahalmenaren arteko loturak. Gainazalaren azterketa sakonek agerian utzi dute gainazal hierarkikoak (mikro- eta nano-egiturak dituztenak) eta gainazal homogeneoak (egitura unitariodunak) daudela, eta topografia propietate berezien erantzule dela. Horrez gain, gaur egun natura imitatzeko eta artifizialki gainazal zimurrak sortzeko oso erabiliak diren goitik beherako eta behetik gorako metodoak deskribatuko dira.

HITZ GAKOAK: topografia, gainazal zimurrak, loto lorea, auto-garbiketa, goitik beherako metodoa, behetik gorako metodoa.

ABSTRACT: Nature provides us with living beings with special characteristics, such as self-cleaning or antibacterial properties. In this work, the connection between surface topography and wetting phenomenon with properties like self-cleaning or bactericidal found in plants, like taro or lotus flower, and some animals will be explained. Regarding surface structures, hierarchical surfaces (micro- and nano-structures) and homogeneous surfaces (unitary structures) can be found, which will have an effect on surface characteristics. Finally, top-down and bottom-up approaches, which nowadays are used to imitate nature and create artificial rough surfaces, will be described.

KEYWORDS: topography, rough surfaces, lotus flower, self-cleaning, top-down, bottom-up.

\footnotetext{
* Harremanetan jartzeko / Corresponding author: Leyre Perez Alvarez. Kimika Fisika Saila. Zientzia eta Teknologia Fakultatea. Euskal Herriko Unibertsitatea UPV/EHU. Sarriena auzoa z/g 48940, Leioa, Bizkaia, Euskal Herria. - leyre.perez@ehu. eus - https://orcid.org/0000-0003-0543-4134.

Nola aipatu / How to cite: Barroso, Nagore; Moreno, Maria Isabel; Perez, Leyre (2019). "Gainazal-topografiak naturan duen eragina»; Ekaia, 35, 2019, 213-223. (https://doi.org/10.1387/ekaia.19722).

Jasoa: 15 maiatza, 2018; Onartua: 20 iraila, 2018

ISSN 0214-9001 - eISSN 2444-3255 / (c) 2019 UPV/EHU
}

cc)(i) () Obra hau Creative Commons Atribución 4.0 Internacional-en lizentziapean dago 


\section{SARRERA}

Naturan, betidanik izan diren eta gizakia liluratu dituen material anitz aurkitu daitezke. Duela bi mila urte baino gehiago, propietate ezin hobeak behatu ziren zenbait landaretan; horien artean, loto lorea (Nelumbo nucifera) da gehien aztertu dena [1]. Lore hau xahutasunaren sinboloa izan da zenbait erlijiotan [2], ingurune zikinetan egonda ere garbi mantentzeko gaitasuna baitu; horri auto-garbitzeko gaitasuna ( $«$ self-cleaning») deritzo, eta gainazal superhidrofoboen ondorioa da [3]. Gainazal hauek kontaktu-angeluaren balioagatik ezaugarritu daitezke; kontaktu-angelua $(\theta)$ solidoaren gainazalak eta ur-tantaren arteko ukitzaileak sortzen duten angeluari deritzo (1a irudia), eta gainazal superhidrofoboetan $150^{\circ}$ baino handiagoa izan behar du. Material superhidrofoboei buruz hitz egiten denean, kontaktu-angeluaren histeresia $\left(\theta_{\mathrm{H}}\right)$ eta irristatze-angeluaren $\left(\theta_{\mathrm{SL}}\right)$ balio txikiei buruz $\left(<10^{\circ}\right)$ [4] ere hitz egiten da (1b irudia). Kontaktu-angeluaren histeresiak aurreratze-kontaktu angeluaren (tantari ur-bolumena gehitzean determinatzen dena, $\theta$ a) eta atzeratze-kontaktu angeluaren (tantari ur-bolumena kentzean neurtua, $\theta$ r) arteko diferentzia adierazten du, eta irristatze-angeluak, berriz, pisu jakin bateko ur-tantek plano oker batean zehar irristatzeko behar duten angeluaren balio kritikoa ematen du.

a)

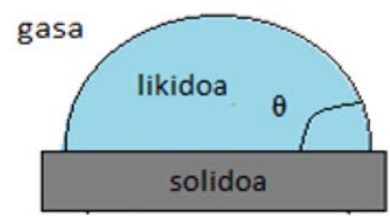

b)

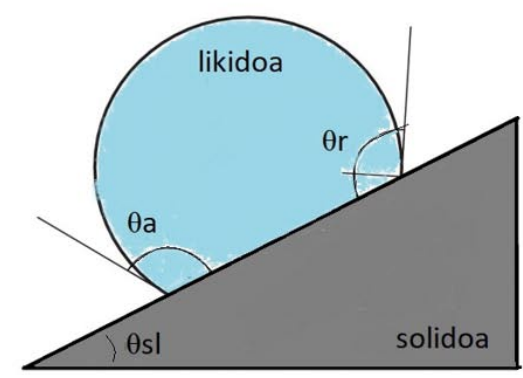

1. irudia. a) kontaktu-angelua b) kontaktu-angeluaren histeresia ( $\theta$ a eta $\theta$ r-ren arteko diferentzia) eta irristatze-angelua $\left(\theta_{\mathrm{SL}}\right)$

Loto loreak erakusten duen auto-garbiketarako berezitasunari erreferentzia egiteko, Barthlott eta haren kolaboratzaileek [5] «loto-efektu» terminoa proposatu zuten. Ikertzaile hauek auto-garbiketarako mekanismoaren oinarriak ere proposatu zituzten, zimurtasunaren, itsaspen-indar txikien eta superhidrofobotasunaren elkarrekiko menpekotasuna agerian utziz. Dena den, ikerketa talde honek erlazio hori esperimentalki frogatu aurretik, Wenzel (1936) eta Cassie-Baxter-ek (1944) bi eredu teoriko [6] garatu zituzten, gainazalen morfologia eta topografia kontaktu-angeluarekin lotuz. Eredu hauetan oinarrituz, gainazal heterogeneoak (mikro- eta nano-egitura hierarkikoa dutenak) eta gainazal homogeneoak (egitura unitariodunak) bereizten dira. 
Loto loreaz gain beste izaki bizidun askok dituzten propietate bereziak ulertzearren, zenbait espezieren gainazaleko egitura aztertzea merezi du. Gainera, naturak eskainitako ezaugarriak imitatu nahian, gaur egun material sintetikoei zimurtasuna emateko erabiltzen diren teknika nagusiak aipatuko dira: goitik beherakoa («top-down») eta behetik gorakoa («bottom-up»), hain zuzen ere.

\section{GAINAZAL ZIMURRAK NATURAN}

Gainazal hierarkikoa duten landareen artean, jadanik aipatutako loto lorea dago [1]. Loto hostoaren (2a irudia) gainazal determinazioa ekorketazko mikroskopio elektronikoaren (SEM) bidez egin da, zeinak materiaren eta elektroien arteko interakzioen ondorioz, erresoluzio altuko irudiak sortzea ahalbidetzen duen: SEM teknikaren bidez lortutako irudiek agerian uzten dute mikro- eta nano-egituraz osatutako gainazal heterogeneoa: 3-10 $\mu \mathrm{m}$-ko tontor eta haranak ( $2 \mathrm{~b}$ irudia), 70-100 nm dituzten argizari-antzeko partikula nanometrikoz osatuak (2c irudia). Mikroegiturak gainazalaren eta uraren arteko kontaktu-azalera txikitzea eragingo du, eta argizaripartikula nanometrikoak, ura aldaratu; oro har, loto lorea superhidrofoboa izatearen erantzule izango dira. Azken hau, kontaktu-angelua eta irristatzeangeluei erreparatuz $\left(161 \pm 2^{\circ}\right.$ eta $3^{\circ}$ hurrenez hurren) ere ondoriozta daiteke [7].
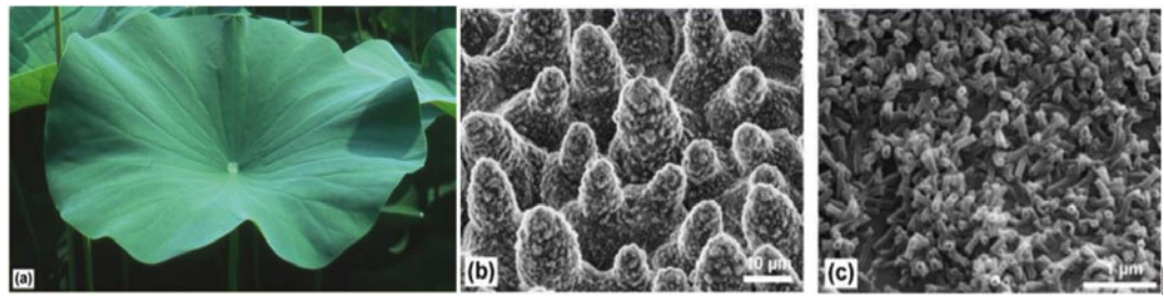

2. irudia. a) Loto hostoa b) eta c) Ekorketazko mikroskopia elektroniko (SEM) bidez lortutako irudiak, hostoaren gainazal hierarkikoa erakutsiz [8].

Arrosa hostoek (Oryza sativa L.), loto lorearen antzeko gainazal egitura eta bustitze-propietateak aurkezten dituzte; kontaktu-angelua $157 \pm 2^{\circ} \mathrm{da}$, eta, beraz, superhidrofoboa [7]. Gainazalaren goiko aldean, 5-8 $\mu \mathrm{m}$-ko egiturak agertzen dira, paraleloki eta norabide bakarrean ordenatuta. Beheko aldean, ordea, proportzionalki sakabanatutako nano-orratzak daude, eta hauek airea harrapatuta gelditzea eragiten dute [1]. Gainazaleko egituren ordenamendu anisotropikoa arrosa hostoen portaera desberdinaren erantzule da; izan ere, irristatze-angelua $4^{\circ}$-koa da norabide batean, eta $12^{\circ}$-koa, ordea, beste batean. Anisotropia hau da loto lorearekiko erakusten duen 
desberdintasunik nabarmenena, azken honek homogeneoki sakabanatutako tontor eta haranak baititu. Beraz, arrosa hostoak aztertuta, ondoriozta daiteke gainazaleko egituren ordenamenduak eragina duela bustitze-ahalmenean [7].

Gainazal konposatua duen beste landare bat ñame (Colocasia esculenta) da. Guo eta haren taldekideek [7] frogatu zuten $10 \mu \mathrm{m}$-ko diametroa duten tontor eliptikoak eta gainazal osoan zehar sakabanatutako orratz nanometrikoak zituela. Bestalde, kontaktu-angelua $159 \pm 2^{\circ}$ eta irristatze-angelua $3^{\circ}$-koa da, hau da, aurreko bi landareak bezala superhidrofoboa. Gainera, ikusi zen loto lorea eta ñame hostoen infragorriko (IR) eta X izpien espektroskopia fotoelektronikozko (XPS) espektroek antzeko emaitzak aurkezten dituztela [7], gainazaleko konposizio kimikoaren antzekotasunak iradokiz. Horrez gain, gainazala estaltzen duen argizaria karbonoz eta oxigenoz osatuta dagoela ikusi zuten. Ma eta haren kolaboratzaileek [9] ñame hostoek bakterioen aurkako propietateak aurkezten dituztela ikusi zuten, eta hostoak bustita egon arren propietate hori mantentzen dutela frogatu zuten. Hasiera batean, bakterioen aurkako propietateak erregimen lehorrean aztertu zirenean, uste izan zuten nano-egituretan harrapatutako airearen ondoriozkoak direla, baina erregimen bustian aztertu ondoren, frogatu zuten nano-egiturak dituzten guneek bakterioekiko itsaspen indar txikiak dituztela.

Fengek [10] arrosa gorriaren petaloek $16 \mu \mathrm{m}$ diametroko zelula konikoak eta $730 \mathrm{~nm}$-ko nano-egiturak dituztela frogatu zuen; horrez gain, kontaktu-angeluaren balioa determinatu zuen, $152.4^{\circ}$ arrosaren gainazal superhidrofoboa eta hierarkikoa dela ondorioztatuz. Loto lorearekin alderatuz, kontaktu-angeluaren balioa antzekoa dela ikus daiteke, baina histeresi-angelua, berriz, handiagoa. Gainera, mikro- eta nano-egiturak loto lorearenak baino handiagoak dira, eta horren ondorioz, urak mikroegiturak zeharkatu ditzake, baina nano-egiturak [11], ordea, ez. Horri «petalo-efektua» deritzogu, non ur-tantak hostoetan itsatsita gelditzen diren, buruz behera egon arren [12].

Orain arte artikulu honetan aztertu diren egituren artean, egitura hierarkikoa duten landare superhidrofoboak deskribatu dira. Hala ere, naturan gainazal homogeneoa duten landareak ere aurkitu daitezke, adibidez, asun zuriaren hostoak (Boehmeria nivea). Kasu honetan, hostoen aurpegi bakoitzak izaera desberdina aurkezten du. Alde batetik, mikro-zuntzak eta mikra-tamainako esferak gainazal osoan zehar sakabanatuta agertzen dira, airea harrapatzea eragotziz. Honen eraginez, gainazal baten tamaina handitzeko egin behar den lana (gainazal-energia askea) handiagoa izango da, hau da, hidrofiloagoa. Kontaktu-angeluaren balioa $38 \pm 2^{\circ}$-koa dela ikustean ere ondorio bera atera daiteke. Hostoen beste aurpegiek, aldiz, kontrako jokaera daukate. Gainazal osoan zehar 1-2 $\mu \mathrm{m}$-ko zuntzak sakabanatuta agertzen dira, egitura unitarioa sortuz eta airea harrapatzea faboratuz. 
Aire horrek gainazal-energia askea murriztuko du, eta $164 \pm 2^{\circ}$-ko kontaktu-angelua lortu; gainazal superhidrofoboa, hain zuzen ere. Asun hostoen antzeko egitura unitarioa sandia txinatarraren azalean ere aurkitu daiteke. Gainazal homogeneodun landare hauek aztertuta, superhidrofobotasuna gainazal hierarkikoekin baina baita homogeneoekin ere lor daitekeela ondoriozta daiteke [7].

Landareek bezala, animaliek ere topografiaren ondoriozkoak diren berezitasunak dituzte. Hasteko, lainoek (ur-bapore kondentsatua, $190 \mathrm{~nm}$ edo diametro handiagoko tantak) eltxoen begietan duten eragina aztertu da, hots, lausotzearen aurkako propietateak [3]. Gao eta haren taldekideek [13] hezetasuna eta begien gainazalaren arteko interakzioa aurkitzen saiatu ziren, eltxoen ikusmen onean oinarrituz. Animalia hauen begien egituraren eta morfologiaren ikerketan, ikusi zuten mikra-tamainako (26 $\mu \mathrm{m}$-ko diametroa) ehunka mikro-hemisferioz osatuta dagoela. Hauek omatidio izenez ezagutzen dira, eta bakarkako unitate sentsorial gisa jokatzen dute. Mikrohemisferio bakoitza oso uniformeak diren nano-tamainako egiturez osatuta dago: $101 \pm 7.6 \mathrm{~nm}$-ko diametroa eta haien artean $47.6 \pm 8.5 \mathrm{~nm}$-ko distantzia. Eltxoen begiek aurkezten duten egitura hierarkikoak airea harrapatzea eragiten du, eta ur-tanten eta begien gainazalaren arteko kontaktua murriztu: lausotzearen aurkako propietatea. Loto lorea bezala, eltxoen begiak superhidrofoboak dira, baina propietate desberdinak dituzte; lehenengoak, auto-garbitzeko gaitasuna aurkezten du milimetro tamaina duten ur-tantentzat, eta eltxoek, aldiz, lausotzearen aurkako propietateak mikra-mailako tantentzat. Hau bat dator Zhang-ek eta haren kolaboratzaileek [14] frogatutakoarekin; hau da, loto lorea denbora luzez atmosfera hezean edo ur-azpian mantenduz gero, tanta txikiek gainazal-egituretan sartu eta gainazala busti egiten dute, superhidrofobizitatearen galera eraginez.

Ivanovak eta haren taldekideek [15] txitxarren hegoek bakterio-zelulak hiltzeko gaitasuna dutela ikusi zuten, Pseudomonas Aeruginosa bakterioen itsaspena ikertzen zuten bitartean. Hegoen gainazala uniformeki banatutako nano-egiturez osatuta dago, eta proteinak, kitina eta argizaria ditu osagai kimiko nagusiak. Ikerketa sakonagoen ondorioz, hiltze-mekanismoa oso azkarra zela ikusi zuten. Gainera, zelulen heriotza topografiaren ondoriozkoa zela frogatu zuten eta ez konposizio kimikoarena, hau da, nanoegiturek zelulak zeharkatuz bakterioen heriotza eragiten zutela. Oro har, txitxarren hegoek aurkezten dituzten bakterioen aurkako propietateak topografiaren ondoriozkoak direla frogatu zuten.

Bestalde, gekoak horma bertikalak eskalatzeko gaitasuna dauka, oinen eta hormen arteko solido-solido itsaspen-indar handien ondorioz. Haren oinek ondo lerrokatutako ile mikroskopikoak dituzte, eta 20-70 $\mu \mathrm{m}$-ko luzera eta 3-7 $\mu \mathrm{m}$-ko diametroa dute. Ileak $\alpha$ - eta $\beta$-keratinaz osatuta daude (itsaspenean eragina dutenak), eta bakoitza milaka espatula nanometrikotan banatzen da, 100-200 nm-ko diametroarekin. Autumn-ek eta haren 
kolaboratzaileek [16] frogatu zuten geko oinak superhidrofoboak zirela (kontaktu-angelua $160 \pm 1.4^{\circ}$ ) eta gainera itsaspen-indar oso handikoak, urtantak itsatsita gelditzearen eraginez, buruz behera jarri arren.

Laburbilduz, bai landareek eta bai animaliek dituzten zenbait propietate bitxik gainazal topografiaren ondoriozkoak direla erakutsi da, egitura homogeneo zein dualak hornituta. Gainazal zimurrek, auto-garbitzeko gaitasunaz gain, loto loreak aurkezten duen bezala, beste propietate batzuk ere badituzte, bakterioen aurkako propietateak, esate baterako. Gainera, egitura hierarkikoak gainazal superhidrofoboak izateko baldintza ez-beharrezkoa dela ere ikusi da (asun zuriaren hostoen kasuan bezala). Naturak eskaintzen dituen ezaugarri hauek, artifizialki erreproduzitu daitezke aplikazio anitzetan eta propietate ezin hobeak dituzten materialak lortzeko. Prozesu hau biomimetika («biomimetic») izenez ezagutzen da ikerketaren munduan; naturak eskaintzen dituen diseinuak kopiatu edo moldatzeko prozesua, alegia $[11,17]$.

\section{GAINAZAL ZIMURRAK PRESTATZEKO METODOAK}

Gainazal zimurrak sortzeko metodoei dagokienez, bi talde nagusi bereiz daitezke: goitik beherako metodoa ( «top-down») eta behetik gorakoa («bottom-up»). Lehenengo metodoak kanpo-faktore esperimentalez kontrolatutako nano-fabrikaziorako erremintak erabiltzen ditu, mikro- eta nanoegiturak materialetan integratuta eraikitzeko. Bigarren metodoa, ordea, gainazalen gainean konposatu atomikoak edo molekularrak metatzean datza, goranzko sintesi-bideari jarraituz (behetik gorako eraldaketa) [18]. Ondoren, bi metodoak aztertuko ditugu.

\subsection{Goitik beherako metodoak}

Goitik beherako metodoa mikroelektronikan erabiltzen den teknika da, materialak zizelkatze edo moldekatze bidez fabrikatzeko erabilia. Kasu honetan, gainazal superhidrofoboak sortzeko, moldekatzea eta litografia dira gehien erabiltzen diren metodoak [19].

\subsubsection{Moldekatzea}

Prozedura honek aurretiaz diseinatutako ama-egitura baten erabilera inplikatzen du, moldekatzearen bidez patroia substratura transferitzeko eta, amaieran, eredua desitsatsi edo disolbatzeko. Ama-egitura gisa loto lorea bezalako lagin naturalak, prozesu litografikoen bidez prestatutako moldeak edo mintz ez-organikoak (anodizatutako aluminazko mintzak, AAO) erabil daitezke. Sun-ek eta haren kolaboratzaileek [20] loto lorea erabili zuten molde gisa, «nanocasting» izeneko prozesua burutuz. Horre- 
tarako, polidimetilsiloxanozko molde negatiboa lortu zuten lehenengo eta hau, eredu bezala erabili zuten erreplika positiboa lortzeko. Azken honek loto lorearen gainazal-morfologia antzekoa zuen, hots, mikro- eta nanoegitura hierarkikoarekin baita bustitze-propietate berdinak, hau da, gainazal superhidrofoboa.

Litografiazko nanoinprimaketa ere patroi-erreplika prozesu bat da, non eredu zurrun bat beira-trantsizio tenperaturaren gainetik dagoen polimero termoplastiko baten kontra presionatzen den (3. irudia). Horrela, ama-egituraren erreplika negatiboa lortzen da [21]. Lee-k eta haren taldekideek [22] teknika hau erabili zuten nano-egituratutako poliestirenoa prestatzeko, superhidrofoboa den substratua lortuz. Topografia simulatzeko porotamaina desberdineko anodizatutako aluminiozko mintzak (AAO) erabili zituzten. Suh-k eta Jonek [23] indar kapilarren bidezko litografia erabiliz eta nano-egituren geometriaz baliatuz, bustitze kontrolatuko polietilenglikola prestatu zuten. Litografia mota honek, nanoinprimaketa bidezkoak ez bezala, molde elastomerikoak (deformazio itzulgarriko polimeroak) erabiltzen ditu.

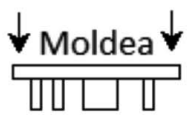

Polimeroa

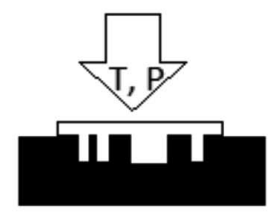

Inprimaketa
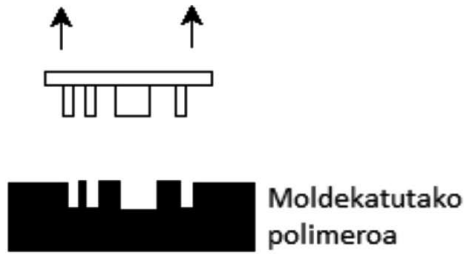

Desmoldekatzea

3. irudia. Litografia bidezko nanoinprimak eta prozedura.

\subsubsection{Fotolitografia}

Kasu honetan, argia molde batean (aurretiaz nahi diren ezaugarriak dituen eta ordenagailuz diseinatua den molde batean) zehar irradiatzen da substratuetara, normalean silizio oxidozkoak direnak. Prozesuan erabiltzen den argi-iturriaren arabera (irradiazioa, elektroiak), bi taldetan banatu daiteke fotolitografia: X izpiko litografia eta elektroi-bonbardaketako litografia. Prozesu honen bidez prestatutako gainazalak errazki karakteriza daitezke, eta oso erabiliak dira gainazalak moldekatzeko.

\subsection{Behetik gorako metodoak}

Goitik beherako metodoan gertatzen ez den bezala, behetik gorako metodoak objektu handiagoen eta konplexuagoen diseinua inplikatzen du, konposatu edo bloke txikiagoen integrazioaren bidez. Nanofabrikazioan, 
behetik gorako metodoak berezko muntaketa («self-assembly») eta berezko antolaketa («self-organization») inplikatzen du, hots, konposatuak espontaneoki disoluzio edo gas fasean batzea, energia minimoko egitura egonkorra lortu arte. Gainazal superhidrofoboen diseinuan, deposizio kimikoa eta geruz-geruzeko deposizioak («layer-by layer») erabil daitezke, esate baterako.

\subsubsection{Deposizio kimikoa}

Metodo honetan, produktu bat substratu egokiaren gainazalean kokatzen da material ez-organikoen geruza kristalino fin bat sortzeko, hala nola, zink sulfuroa $(\mathrm{ZnS})$, kobre (II) seleniuroa $(\mathrm{CuSe})$, kadmio sulfuroa $(\mathrm{CdS})$, etab. dira. Produktua gainazalean nola metatzen den arabera bainu bidezko («chemical bath deposition», CBD) eta bapore bidezko («chemical vapor deposition», CVP) deposizioak bereiz daitezke. Beraz, jalkitze-prozesuak morfologia desberdinak lortzea eragingo du, hala nola, nano-tutuak edo nano-orratzak. Adibidez, Wu-k eta haren kolaboratzaileek [24] zink oxidozko nano-tutuak lortu zituzten CBD bitartez, gainazal superhidrofobikoak prestatzeko.

\subsubsection{Geruz-geruzeko deposizioak}

Teknika sinple eta efektibo honen bidez, substratuak konposatu kimikoekin estal daitezke, geruzen lodiera modu errazean kontrolatuz. Teknika honen abantaila nagusia, prozesuan erabilitako konposatu kimikoen artean sortu ahal diren interakzio motak dira, adibidez, hidrogeno-loturak, kargatransferentziak, koordinazio-loturak eta polielektrolitoen arteko interakzio elektrostatikoak (4. irudia) [25]. Ji-k eta haren taldekideek [26] material antibakterianoa lortu zuten, polietilentereftlato filmen gainean kitosanoa eta heparina txandakatuz prestatua.
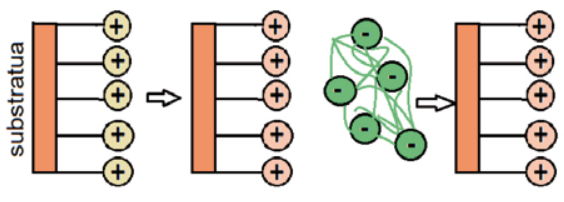

Polianioia

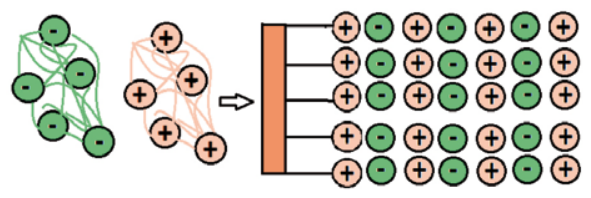

Polianioia Polikatioia

4. irudia. Geruz-geruzeko prozedura polielektrolitodun geruzak sortzeko.

Geruzak eraikitzeko «spin-coating» eta «dip-coating» dira metodo ezagunenetarikoak. Lehenengoan, substratuaren gainean metatu nahi den disoluzio kantitate bat jarri eta abiadura handian biratuz, jariakina gainazal osoan zehar sakabanatzen da. «Dip-coating» teknikan, ordea, substratua disoluzioan murgiltzean datza, antzeko emaitzak lortuz [27]. 


\section{ONDORIOAK}

Naturako izaki bizidunen azterketa sakonak hauek dituzten propietate bitxien zergatia aurkitzea ahalbidetu du. Adibiderik ospetsuena mende askotan xahutasunaren sinbolo gisa hartu den loto lorea dago, honek aurkezten duen auto-garbitzeko gaitasunaren ondorioz. Honez gain, beste hainbat adibide aurkitu ditzakegu, hala nola, ñame hostoek eta txitxarren hegoen bakterioen aurkako propietateak edo eltxoen begiak lausotzearen aurkako propietateak. Kasu guztietan, zerikusia dauka gainazal morfologiak eta egiturak: homogeneoa edo hierarkikoa den, mikro- eta nano-egiturek duten tamaina eta forma, alegia.

Naturak eskaintzen dituen propietate ezin hobe horiek material artifizialetan erreproduzitzera eramaten gaitu. Izan ere, goitik beherako eta behetik gorako teknikek gainazaleko materia desagertuz eta haziz, hurrenez hurren, mikro- eta nano-metrikozko topografia hierarkikoki antolatua lortzea ahalbidetzen dute.

\section{BIBLIOGRAFIA}

[1] GUO, Z.; LIU, W. eta SU, B. L. 2011. «Superhydrophobic Surfaces: From Natural to Biomimetic to Functional». J. Colloid Interface Sci., 353, 335355.

[2] YAN, Y. Y.; GAO, N. eta BARTHLOTT, W. 2011. «Mimicking Natural Superhydrophobic Surfaces and Grasping the Wetting Process: A Review on Recent Progress in Preparing Superhydrophobic Surfaces». Adv. Colloid Interface Sci., 169, 80-105.

[3] DARMANIN, T. 2015. «Superohydrophobic and Superoleophobic Properties in Nature». Mater. Today, 18, 273-285.

[4] FALDE, E. J.; YOHE, S. T. eta COLSON, Y. L.; Grinstaff, M. W. 2016. «Superhydrophobic Materials for Biomedical Applications». Biomaterials, 104, 87-103.

[5] BARTHLOTT, W. eta NEINHUIS, C. 1997. «Purity of the Sacred Lotus, or Escape from Contamination in Biological Surfaces». Planta, 202 (1), 1-8.

[6] BHUSHAN, B. eta NOSONOVSKY, M. 2010. «The Rose Petal Effect and the Modes of Superhydrophobicity». Philos. Trans. R. Soc. A Math. Phys. Eng. Sci., 368, 4713-4728.

[7] GUO, Z.; LIU, W. 2007. «Biomimic from the Superhydrophobic Plant Leaves in Nature: Binary Structure and Unitary Structure». Plant Sci., 172, 1103-1112.

[8] ENSIKAT, H. J.; DITSCHE-KURU, P.; NEINHUIS, C. eta BARTHLOTT, W. 2011. «Superhydrophobicity in Perfection: The Outstanding Properties of the Lotus Leaf». Beilstein J. Nanotechnol., 2, 152-161. 
[9] MA, J.; SUN, Y.; GLEICHAUF, K.; LOU, J. eta LI, Q. 2011. «Nanostructure on Taro Leaves Resists Fouling by Colloids and Bacteria under Submerged Conditions». Langmuir, 27, 10035-10040.

[10] FENG, L.; ZHANG, Y.; XI, J.; ZHU, Y.; WANG, N.; XIA, F. eta JIANG, L. 2008. «Petal Effect: A Superhydrophobic State with High Adhesive Force». Langmuir, 24, 4114-4119.

[11] BHUSHAN, B. eta HER, E. K. 2010. «Fabrication of Superhydrophobic Surfaces with High and Low Adhesion Inspired from Rose Petal». Langmuir, 26, 8207-8217.

[12] LAW, J. B. K.; NG, A. M. H.; HE, A. Y. eta LOW, H. Y. 2017. «Bioinspired Ultrahigh Water Pinning Nanostructures». Langmuir, 30, 325-331.

[13] GAO, X.; YAN, X.; YAO, X.; XU, L.; ZHANG, K.; ZHANG, J.; YANG, B. eta JIANG, L. 2007. «The Dry-Style Antifogging Properties of Mosquito Compound Eyes and Artificial Analogues Prepared by Soft Lithography». Adv. Mater., 19, 2213-2217.

[14] ZHANG, J.; SHENG, X.; JIANG, L.; ZHANG, J.; SHENG, X. eta JIANG, L. 2009. «The Dewetting Properties of Lotus Leaves The Dewetting Properties of Lotus Leaves». Langmuir, 25, 1371-1376.

[15] IVANOVA, E. P.; HASAN, J.; WEBB, H. K.; TRUONG, V. K.; WATSON, G. S.; WATSON, J. A.; BAULIN, V. A.; POGODIN, S.; WANG, J. Y .; TOBIN, M. J.; LÖBBE, C. eta CRAWFORD, R. J. 2012. «Natural Bactericidal Surfaces: Mechanical Rupture of Pseudomonas Aeruginosa Cells by Cicada Wings». Small, 8, 2489-2494.

[16] AUTUMN, K.; SITTI, M.; LIANG, Y. A.; PEATTIE, A. M.; HANSEN, W. R.; SPONBERG, S.; KENNY, T. W.; FEARING, R.; ISRAELACHVILI, J. N. eta FULL, R. J. 2002. «Evidence for van Der Waals Adhesion in Gecko Setae». Proc. Natl. Acad. Sci., 99, 12252-12256.

[17] CELIA, E.; DARMANIN, T.; TAFFIN DE GIVENCHY, E.; AMIGONI, S. eta GUITTARD, F. 2013. «Recent Advances in Designing Superhydrophobic Surfaces». J. Colloid Interface Sci., 402, 1-18.

[18] BISWAS, A.; BAYER, I. S.; BIRIS, A. S.; WANG, T.; DERVISHI, E. eta FAUPEL, F. 2012. «Advances in Top-down and Bottom-up Surface Nanofabrication: Techniques, Applications \& Future Prospects». Adv. Colloid Interface Sci., 170, 2-27.

[19] LI, X.-M.; REINHOUDT, D. eta CREGO-CALAMA, M. 2007. «What Do We Need for a Superhydrophobic Surface? A Review on the Recent Progress in the Preparation of Superhydrophobic Surfaces». Chem. Soc. Rev., 36, 1350.

[20] SUN, M.; LUO, C.; XU, L.; JI, H.; OUYANG, Q.; YU, D. eta CHEN, Y. 2005. «Artificial Lotus Leaf by Nanocasting». Langmuir, 21, 8978-8981.

[21] DEL CAMPO, A. eta ARZT, E. 2008. «Fabrication Approaches for Generating Complex Micro- and Nanopatterns on Polymeric Surfaces». Chem. Rev., 108, 911-945. 
[22] LEE, W.; JIN, M.; YOO, W. eta LEE, J. 2004. «Nanostructuring of a Poymeric Substrate with Wll-Defined Nanometer-Scale Topography and Tailored Surface Wettability». Langmuir, 20, 7665-7669.

[23] SUH, K. Y. eta JON, S. 2005. «Control over Wettability of Polyethylene Glycol ( PEG ) Surfaces Consisting of Complex Nanostructures». Langmuir, 21, 6836-6841.

[24] WU, X.; ZHENG, L. eta WU, D. 2005. «Fabrication of Superhydrophobic Surfaces from Microstructured ZnO-Based Surfaces via a Wet-Chemical Route». Langmuir, 21, 2665-2667.

[25] YAO, L. eta HE, J. 2014. «Recent Progress in Antireflection and Self-Cleaning Technology - From Surface Engineering to Functional Surfaces». Prog. Mater. Sci., 61, 94-143.

[26] FU, J.; JI, J.; YUAN, W.; SHEN, J. 2005. «Construction of Anti-Adhesive and Antibacterial Multilayer Films via Layer-by-Layer Assembly of Heparin and Chitosan». Biomaterials, 26, 6684-6692.

[27] SAHOO, B. N. eta KANDASUBRAMANIAN, B. 2014. «Recent Progress in Fabrication and Characterisation of Hierarchical Biomimetic Superhydrophobic Structures». RSC Adv., 4, 22053. 